\title{
SEPSIS: EMERGING ROLE OF NITRIC OXIDE AND SELECTINS
}

\author{
Abhijit Chandra ${ }^{\mathrm{a}}$, Perenlei Enkhbaatar ${ }^{\mathrm{b}}$, Yoshimitshu Nakano ${ }^{\mathrm{b}}$,Lillian D Traber ${ }^{\mathrm{b}}$, \\ and Daniel L. Traber ${ }^{b}$
}

Chandra A, Enkhbaatar P, Nakano Y, Traber LD, Traber DL. Sepsis: emerging role of nitric oxide and selectins. Clinics. 2006;61(1):71-6.

Sepsis - a state of systemic bacterial infection — often leads to multiorgan failure and is associated with high mortality despite the recent advances achieved in intensive care treatment. Many of the ill effects of sepsis are attributed to an abnormally enhanced host inflammatory response that leads to neutrophil recruitment and activation involving selectins, a class of adhesion molecules, in the initial stages. Nitric oxide and its various isoforms have also been implicated in various vascular alterations and directly participate in the cellular toxicity in sepsis. This review briefly describes the role of selectins and nitric oxide in experimental and clinical sepsis as well as the therapeutic outcomes of blocking therapies.

KEYWORDS: Sepsis. Selectins. Nitric oxide. Multiorgan failure.

Sepsis, a state of severe, sustained bacterial infection, runs through phases of very low blood pressure leading to dangerously reduced oxygen delivery to the tissues and frequently to multiorgan dysfunction. . Even today, this lifethreatening complication of infection is associated with significant morbidity and mortality in the intensive care unit, where it is the most common cause of mortality.

Many of the adverse outcomes of severe sepsis can be traced to an abnormally enhanced inflammatory response. Leukocyte activation and adhesion to the endothelium in various tissues play important roles in host defense and repair of tissue damage. Under some conditions, leukocyte adhesion to the endothelium may contribute to vascular and tissue damage, and to organ dysfunction.

These leukcocyte-endothelial interactions, which may also contribute to inflammation-mediated injury, involve a group of adhesion molecules - the selectins. Because

aDepartment of Surgery, King George Medical University - Lucknow, India. ${ }^{b}$ Department of Anesthesiology, University of Texas Medical Branch, Galveston, Texas.

Email:dltraber@utmb.edu

Received for publication on August 05, 2005.

Accepted for publication on October 14, 2005. leukocytes must adhere to the endothelium to emigrate to the tissue, blockade of leukocyte-endothelial adhesive interactions has the potential to reduce vascular and tissue injury in sepsis and in the systemic inflammatory response (SIRS) syndrome. ${ }^{1}$

Nitric oxide (NO) is believed to play a key role in the pathogenesis of septic shock, although many aspects of the involvement of NO remain poorly defined. The elevated circulating nitrite/nitrate - the stable byproducts of NO observed in septic patients - combined with the reduction in vascular tone seen after endotoxin or proinflammatory cytokine administration, and the identification of endothelium-derived relaxing factor (EDRF) as $\mathrm{NO},{ }^{2}$ led to the suggestion that NO is involved in the cardiovascular alterations of septic shock. ${ }^{3}$ Our work has focused on elucidating the mechanisms of action of NO and selectins in sepsis and acute respiratory distress (ARDS). This review briefly discuses recent findings on the role of selectins and NO in sepsis and therapies directed at blocking their responses.

\section{SELECTINS IN SEPSIS}

Recruitment and activation of leukocytes in various tis- 
sues to eradicate infection remain central features in the septic response. The interaction between complementary adhesion molecules and ligands induced by bacterial products and inflammatory mediators initiate leukocyte recruitment. ${ }^{4}$ Weak adhesion, or rolling, follows initial contact. This process is predominantly mediated by selectins, a major class of adhesion molecules involved in the earliest step of neutrophil emigration and in the early events of the acute inflammatory process. These molecules mediate initial contact between polymorphonuclear cells and endothelial cells, resulting in a "rolling" phenomenon, in which the leukocytes adhere intermittently to the endothelial cells.

The selectin family is comprised of 3 proteins designated by the prefixes $\mathrm{E}$ (endothelial), $\mathrm{P}$ (platelet), and $\mathrm{L}$ (leukocyte). Both E- and P-selectins are expressed by endothelial cells, whereas L-selectin is expressed on leukocytes. ${ }^{5}$ P-selectin is synthesized constitutively by endothelial cells and platelets and stored in Weibel-Palade bodies or alpha granules. ${ }^{6} \mathrm{P}$-selectin rapidly surfaces on endothelial cells after activation by histamine, leukotrienes, thrombin, oxidants, and complement. ${ }^{6}$ E-selectin, an endothelial selectin, is induced by cytokines such as interkeukin-1 and endotoxin. ${ }^{7}$ On activation by endothelial cells, L-selectin undergoes a conformational change and, once released, becomes a soluble protein that concentrates in the plasma. ${ }^{5}$

The rolling leukocytes come into close contact with endothelial cells, integrins, and intercellular adhesion molecules to initiate firm adhesion. The combination of these two processes results in leukocyte binding to endothelium. Firm adhesion of leukocytes causes endothelial damage and allows the leukocyte to transmigrate into the surrounding tissues. ${ }^{6}$ The uncontrolled leukocyte activation, adhesiveness, and sequestration in the microcirculation results in release of toxic products such as elastase and oxygen superoxide $\left(\mathrm{O}^{2-}\right)$ and leads to endothelial damage, which in turn leads to many of the hemodynamic and inflammatory derangements that result in septic shock and, eventually, multiorgan failure (Fig. 1). ${ }^{8}$ The proinflammatory mediator surge in severe sepsis leads to a widespread up-regulation of these adhesion molecules and may also involve sites distant from primary infection. ${ }^{8}$ Therefore, activated neutrophils can adhere to and damage the endothelium of noninfected tissues as well, and leukocyte activation can even predict outcome in septic patients. Immuno-neutralization of selectins could therefore decrease the neutrophil adhesion and transmigration and hence, neutrophil-induced local and systemic tissue damage.

There are several potential approaches to inhibit leukocyte adhesion to the endothelium. The most direct approach is to block receptor-ligand interactions.

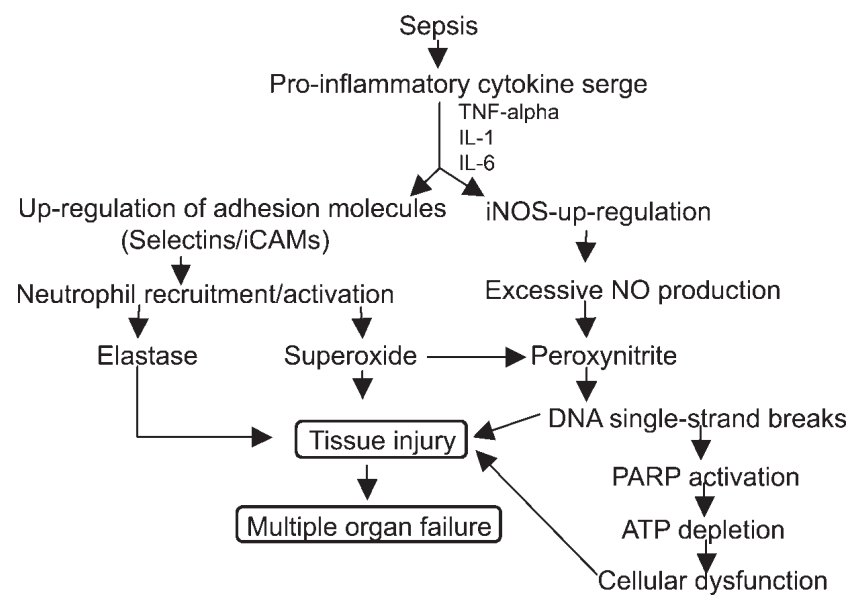

Figure 1 - Role of selections and excessive nitric oxide in sepsis-related tissue injury.

Monoclonal antibodies of murine origin have been used extensively in anti-adhesion therapy in a variety of preclinical studies and several clinical trials. ${ }^{9-11}$ For most clinical trials, humanized monoclonal antibodies have been developed to prevent an immune response against murine protein structures. However, small molecules that bind to the ligand recognition site of leukocyte integrins ${ }^{12}$ and block interaction with the surface ligands of integrins or allosterically modify the the receptor ${ }^{13}$ are also under development. Another approach is to develop drugs that inhibit the pathways involved in "inside-out" signaling of leukocyte integrins. Antisense oligonucleotides have been developed that target specific messenger RNAs, blocking translation or destabilizing the message, with subsequent reduction in surface expression of endothelial adhesion molecules such as intercellular adhesion molecule-1.14 A more global approach is to inhibit nuclear factor-kB, a pivotal transcription factor in the immune-inflammatory response. ${ }^{15}$ Nuclear factor-kB regulates the expression of genes of several critical pro-inflammatory endothelial molecules such as intercellular adhesion molecule-1, vascular cell adhesion molecule-1, E-selectin, and interleukin-8. Post-trafficking events (i.e., those occurring after the leukocyte has migrated across endothelial cells and entered tissue) are also potential therapeutic targets. Blockade of integrin receptors on tissue leukocytes has been shown to attenuate inflammatory-immune responses in animal models, perhaps by modulating "outside in" signaling involved in leukocyte activation or apoptosis. ${ }^{16,17}$ None of the anti-adhesion therapies have, however, proven to be of any clinical benefit to date. $^{9-11,18-20}$

Of particular interest are the two traumatic-shock studies by Rhee et al. ${ }^{8}$ and Vedder et al. ${ }^{19}$ Both trials, using humanized CD 18 monoclonal antibodies to prevent neu- 
trophil adhesion to endothelium, tested the hypothesis that activated neutrophils play a pivotal role in reperfusion injury after resuscitation from traumatic shock. Both trials were prospective, placebo-controlled, randomized, multicenter, double-blinded, phase 2 trials in patients with blunt and penetrating trauma. Notably, although these trials enrolled patients at high risk of infection, there was no increase in infectious complications such as pneumonia in patients receiving the humanized monoclonal antibodies to CD 18. The trial by Rhee et al. showed a decreasing trend in the median length of stay in the intensive care unit and a favorable trend in the median days on the ventilator. In those patients receiving the highest dose of CD 18 monoclonal antibodies, Vedder et al. noted a trend of improvement in acute respiratory distress (ARDS) syndrome on days 1 through 3 and a significant reduction in pulmonary and cardiac organ failure (Denver multiple organ failure) on day 2. However, in both trials, mortality and other primary end points were not significantly affected. A more recent study by Ferri et $\mathrm{al}^{20}$ concluded that elevated concentrations of L-selectins are found in human sepsis. A few other studies have shown that septic patients shed Lselectin. ${ }^{21}$ Our own experimental studies have shown that the pulmonary microvascular response in our ARDS model can be blocked by the administration of anti-L-selectin antibody, LAM (leukocyte adhesion molecule )-(1-3), the $\mathrm{F}(\mathrm{ab}) 2$ portion of the monoclonal antibody to L-selectin. ${ }^{22}$ However, we have also observed that the anti-P-selectin antibody fails to prevent the activation process involved in the deposition of leukocytes in the pulmonary microcirculation (i.e. rolling or change in cellular plasticity), but this selectin may be involved in leukocyte degranulation and may somehow decrease peripheral oxidative tissue metabolism. ${ }^{23}$ The possible reasons for failure of anti-P-selectin antibody to prevent the activation process could be related to the timing of its administration, since P-selectin is expressed very early in the inflammatory process. It is also known that there are selectin-independent mechanisms of neutrophil recruitment in the lung.

\section{NITRIC OXIDE IN SEPSIS}

Nitric oxide (NO), a ubiquitous biological molecule produced by numerous cell types, is implicated in a wide range of disease processes, exerting both detrimental and beneficial effects at the cellular and vascular levels. Sepsis is one area where $\mathrm{NO}$ is thought to play a key role in pathogenesis. Importantly, most NO research has been conducted on animal models. In attempting to understand the complexities of NO in sepsis and interpret the many apparently conflicting results available, it is important to re- member that the situation can vary according to the species being studied, the model of sepsis employed, the concentrations of NO involved. Also, the timing of measurements and observations may vary according to the type of receptor blockade employed.

NO synthesis requires oxidation of a single guanidino nitrogen atom of L-arginine, a process involving the oxidation of nicotinamide adenosine dinucleotide phosphate (NADPH) and the reduction of molecular oxygen. The major NO synthase (NOS) isoforms identified can be broadly grouped together as constitutive NOS (cNOS) and inducible NOS (iNOS). Constitutive NOS includes nNOS (neuronal NOS or NOS1) and eNOS (endothelial NOS or NOS3). The cDNA for these isoforms has been localized in several species, including humans. Constitutive NOS, either neuronal or endothelial, is always present but is relatively inactive until intracellular calcium levels rise. The small amounts of NO produced by the calcium-dependent cNOS are involved in various physiologic processes, including neurotransmission and regulation of the vascular tone regulation. ${ }^{25,27}$

Inducible NOS (or NOS2) is not active under normal conditions, although the enzyme may be detected in some cell types, including lung, small intestine, and platelets. In sepsis, when certain cells are activated by specific proinflammatory agents such as endotoxin, tumor necrosis factor alpha (TNF-alpha), interferon-gamma (IFN), and interleukin-1 (IL-1), iNOS activity is induced. The activation of human iNOS involves transcription of messenger ribonucleic acid (mRNA), which is triggered by the binding of transcription factors, including nuclear factor-kappa B (NF-kB), IFN-regulatory factor-1 (IRF-1), c-jun, c-fos, and signal transducer and activator of transcription (STAT)1 to specific sites on the promoter of the iNOS gene. The activation of the newly synthesized iNOS requires post-transcriptional alterations and the presence of substrate and cofactors, including calmodulin. Calcium, although not required for calmodulin binding to iNOS, may also be important in the induction of iNOS mRNA. Once induced, large amounts of NO are produced by iNOS, provided that the availability of L-arginine, a substrate for biosynthesis of NO, is available.

In addition, to the activation of iNOS, cytokines and endotoxin may increase NO release by increasing arginine availability through the opening of the specific channels and through the expression of the cationic amino acid transporter (CAT), or by increasing tetrahypdrobipterin levels, a key cofactor in NO synthesis. ${ }^{32}$

The functional status of cNOS in endotoxemia and sepsis has not been fully elucidated. Several experimental studies have demonstrated a decrease in cNOS activity result- 
ing in an impairment in endothelial-dependent relaxation during endotoxemia and experimental sepsis, ${ }^{25,26}$ possibly as the result of a cytokine- or hypoxia-induced shortened half-life of cNOS mRNA,${ }^{27}$ or because of altered calcium mobilization. ${ }^{28}$ Other investigators have shown increased endothelial NO release immediately after endotoxin administration either directly ${ }^{29}$ or indirectly from the lack of effect of a specific iNOS inhibitor on the initial hypotension after endotoxin. The activity of endothelial NO in sepsis can actually transiently increase and then decrease later.

The pathogenic role of NO in sepsis and septic shock can, in fact, encompass both vascular alterations and the direct cellular toxic effects of NO or NO-related compounds. At high concentrations, NO becomes a potential proinflammatory and cytotoxic factor by reacting with $\mathrm{O}^{2-}$ to form the toxic product, $\mathrm{ONOO}^{-}$(peroxynitrite), and may cause tissue damage (Fig. 1). In several experimental models, endotoxin has been shown to increase the constitutive release of $\mathrm{NO}$ by the endothelium and the activity of the iNOs enzyme. ${ }^{28}$ Mice lacking iNOS have been reported to be resistant to endotoxin-induced mortality ${ }^{30}$ and vascular hypocontractility, ${ }^{31}$ supporting a key role for iNOS in endotoxin shock. In addition to endotoxin, cell wall components and enterotoxin from gram-positive organisms are also able to stimulate NO release.

Many experimental agents have been employed in atempts to block the effects of NO. The first agents to be used were competitive analogs of L-arginine. Interestingly, the uptake of these compounds by endothelial cells and macrophages can be influenced by cytokine or endotoxin administration, presumably via the $\mathrm{y}+$ channels. ${ }^{32} \mathrm{~L}$-canavanine, L-lysine, $\mathrm{L}$-thiocitrulline, and their derivatives have been proposed as relatively selective iNOS inhibitors. In general, beneficial effects have been observed with inhibitors which are selective for iNOS, or with low doses of nonisoform selective inhibitors, whereas high doses of nonisoform selective NOS inhibitors have been detrimental. Aminoguanidine ${ }^{33}$ and L-canavanine, ${ }^{34}$ both selective inhibitors, have been shown to be of benefit in experimental sepsis. Both the inhibitors provided renal and hepatic protection in addition to attenuating circulatory failure.

The role of NO antagonists has also been studied in the clinical setting. In a study of 12 patients with severe sepsis, L-NMNA (N omega monomethyl-L-arginine) caused an increase in blood pressure and systemic vascular resistance with a fall in cardiac output. ${ }^{35}$ Continuous infusion of L-NAME (N omega-nitro-L-arginine methyl ester) also improved arterial pressure and oxygenation in septic patients. ${ }^{36}$ An increase in blood pressure and systemic vascular resistance with a decreased cardiac output in patients receiving $\mathrm{N}$ nitro-L-arginine has been reported. ${ }^{37}$
Although most of these studies have reported beneficial effects on hemodynamic status, NOS inhibition results in raised pulmonary vascular resistance, and its effects on overall outcome remain inconclusive. A recent study had to be aborted due to high mortality in the treatment group. More recently, it was reported that another nonselective NOS inhibitor, 546C88, increased mortality in patients with septic shock. ${ }^{38}$ There are studies that have indicated that nNOS may be induced in the pathological condition. ${ }^{39}$, We have recently reported that 7-nitroindazole, a specific nNOS inhibitor, reversed the pathological changes in our experimental model ${ }^{40}$ We have also shown a beneficial effects of inhibition of iNOS-derived excessive NO in our burn and smoke inhalation injury-induced ARDS model in sheep. Thus, the debate over whether the inhibition of NO is beneficial or harmful, as well as whether the excessive amount of NO should be suppressed, and what isoform should be targeted, still continues. It is possible that certain NOS isoforms could be expressed at certain time points depending on the type of injury. More targeted and selective inhibition of NOS isoforms using truly selective NOS inhibitors at their maximal activity could be beneficial in the management of multiorgan failure associated with sepsis.

\section{CONCLUSION}

Leukcocyte-endothelial interactions and NO are believed to play a key role in the pathogenesis of septic shock, although many aspects of their involvement remain poorly defined.

The selectin family of adhesion molecules mediates the initial attachment of leukocytes to venular endothelial cells before their firm adhesion and diapedesis at sites of tissue injury and inflammation. Leukocyte rolling and adhesion to endothelium is mediated in part by selectins, which not only mediate their passive adsorption to endothelial surface but also direct these processes. Also important are a host of locally active inflammatory mediators and chemokines responsible for initiating and perpetuating the inflammatory process.

Selectin-directed therapeutic agents are proving to be effective in blocking many of the pathological effects resulting from leukocyte entry into sites of septic inflammation. Future studies need to be focused on how selectins interact with the increasing array of other adhesion molecules and inflammatory mediators that are being identified.

It is now established that $\mathrm{NO}$ plays an important role in the pathogenesis of ARDS, sepsis, and multiple organ failure. However, in recent studies involving animals and humans, suppression of excessive amounts of NO in sepsis has 
not proven to be of significant benefit. There is still controversy on whether inhibition of NO is beneficial or harmful, on whether NO needs to be suppressed, or which isoform is really important. Future treatment strategies may need to be more selective in inhibiting NOS isoforms to yield benefit.

Thus, most of the studies that attempt to inhibit the effects of selectins and NO are experimental and involve ani- mal models, although the results of a few human (clinical) trials are also available. To date, none of the trials has provided a definite answer in terms of elucidating the molecular mechanisms involved or in terms of showing a clinical benefit. There is a clear need for the development of more potent and selective receptor antagonists for more specific selectins and specific inhibitors for NOS isoforms.

\section{RESUMO}

Chandra A, Enkhbaatar P, Yoshimitshu N, Traber LD, Traber DL. Sepse: o papel das selectinas e do óxido nítrico. Clinics. 2006;61(1):71-6.

Sepse - um estado de infecção bacteriana sistêmica - frequentemente leva à falência múltipla de órgãos e associase a altos índices de mortalidade, apesar de progressos recentes no manejo de pacientes em unidades de terapia intensiva. Muitos dos efeitos maléficos associados à sepse são atribuídos a uma resposta inflamatória patologicamente ampliada que leva a recrutamento neutrofílico e ativação das moléculas de adesão do grupo das selectinas, durante as fases iniciais do processo . O óxido nítrico e sua diversas isoformas também foram implicados nas diversas manifestações vasculares da sepse como participantes diretos da toxicidade celular. Esta revisão descreve o papel das selectinas e do óxido nítrico em situações clínicas e experimentais de sepse, bem como os respectivos efeitos de processos terapêuticos de bloqueio.

UNITERMOS: Sepse. Selectinas. Óxido nítrico. Falência múltipla de órgãos.

\section{REFERENCES}

1. Corenjo CJ, Winn RK, Harlan JM. Antiadhesion therapy. Adv pharmacol. 1997,39:99-142.

2. Clancy RM, Leszczynska-Piziak J, Abramson SB. Nitric oxide, an endothelial cell relaxation factor, inhibits neutrophil superoxide anion production via a direct action on the NADPH oxidase. J Clin Invest. 1992;90:1116-21

3. Panas D, Khadour Szabo FH, Szabo C, Schulz R. Proinflammatory cytokines depress cardiac efficiency by a nitric oxide-dependent mechanism. Am J Physiol. 1998;275:H1016-23.

4. Barroso-Aranda J, Zweifach BW, Mathison JC, Schmid-Schonbein GW Neutrophil activation, tumour necrosis factor, and survival after endotoxic and hemorrhagic shock. J Cardiovas Pharmacol. 1995;25, Suppl 2:S25-29.

5. Tedder TF, Steeber DA, Chen A, Engel P. The selectins: vascular adhesion molecules. FASEB J. 1995;9:866-73.

6. Korshuis RJ, Adherson DC, Granger DN. Role of neutrophil-endothelial cell adhesion in inflammatory disorders. J Crit Care. 1994;9:47-71.

7. Williams TJ, Hellewell PG. Endothelial cell biology. Adhesion molecules involved in the microvascular inflammatory response. Am Rev Respir Dis. 1992;146:S45-50.

8. Parent C, Eichacker PQ. Neutrophil and endothelial cell interactions in sepsis. The role of adhesion molecules. Infect Dis Clin North Am. 1999; 13:427-47.
9. Haug CE, Colvin RB, Delmonico FL, Auchincloss H Jr, Tolkoff-Rubin N, Preffer FI, et al. A phase I trial of immunosuppression with antiICAM-1 (CD54) mAb in renal allograft recipients. Transplantation. 1993;55:766-72.

10. Enlimomab Acute Stroke Trial Investigators. Use of anti-ICAM-1 therapy in ischemic stroke: results of the Enlimomab Acute Stroke Trial. Neurology. 2001,57:1428-34.

11. Kavanaugh AF, Davis LS, Jain RI, Nichols LA, Norris SH, Lipsky PE. A phase I/II open label study of the safety and efficacy of an anti-ICAM1 (intercellular adhesion molecule-1; CD54) monoclonal antibody in early rheumatoid arthritis. J Rheumatol. 1996;23:1338-44.

12. Abraham WM, Gill A, Ahmed A, Sielczak MW, Lauredo IT, Botinnikova Y, et al. A small-molecule, tight-binding inhibitor of the integrin alpha (4) beta (1) blocks antigen-induced airway responses and inflammation in experimental asthma in sheep. Am J Respir Crit Care Med. 2000;162:603-11.

13. Weitz-Schmidt G, Welzenbach K, Brinkmann V, Kamata T, Kallen J, Bruns C, et al. Statins selectively inhibit leukocyte function antigen-1 by binding to a novel regulatory integrin site. Nat Med. 2001;7:687-92.

14. Schreiber S, Nikolaus S, Malchow H, Kruis W, Lochs H, Raedler A, et al. Absence of efficacy of subcutaneous antisense ICAM-1 treatment of chronic active Crohn's disease. Gastroentrology. 2001;120:1339-46.

15. Barnes PJ, Karin M. Nuclear factor-kappaB: a pivotal transcription factor in chronic inflammatory disease. N Engl J Med. 1997;336:1066-71. 
16. de Fougerolles AR, Sprague AG, Nickerson-Nutter CL, Chi-Rosso G, Rennert PD, Gardner H, et al. Regulation of inflammation by collagenbinding integrins alpha1beta 1 and alpha2beta 1 in models of hypersensitivity and arthritis. J Clin Invest. 2000,105:721-29.

17. Henderson WR Jr, Chi EY, Albert RK, Chu SJ, Lamm WJ, Rochon Y, et al. Blockade of CD49d (alpha4 integrin) on intrapulmonary but not circulating leukocytes inhibits airway inflammation and hyperresponsiveness in a mouse model of asthma. J Clin Invest. 2000;105:721-9.

18. Rhee P, Morris J, Durham R, Hauser C, Cipolle M, Wilson R, et al. Recombinant humanized monoclonal antibody against CD18 (rhuMAb CD18) in traumatic hemorrhagic shock: results of a phase II clinical trial. Traumatic Shock Group. J Trauma. 2000;49:611-19.

19. Vedder NB, Harlan J,Winn R, et al. Immunomodulator: inhibitors of adhesion (Abstract \#1). 5TH World Congress of Trauma, Shock, Inflammation and Sepsis-Pathophysiology, Immune Consequences and Therapy. Feb 29TH- March 4TH, 2000, Munich, Germany. Shock 2000;13(Suppl 1):1.

20 Ferri LE, Pascual J, Seely AJ, Chaudhury P, Christou NV. Soluble Lselectin attenuates tumor necrosis factor-alpha-mediated leukocyte adherence and vascular permeability: a protective role for elevated soluble L-selectin in sepsis. Crit Care Med. 2002;30:1842-47.

21. Ahmad NA, Christau NV. Decreased neutrophil L-selectin expression in patients with systemic inflammatory response syndrome. Clin Invest Med. 1996;19:427-34.

22. Katahira J, Murakami K, Schmalstieg FC, Cox R, Hawkins H, Traber $\mathrm{LD}$, et al. Role of anti-L-selectin antibody in burn and smoke inhalation injury in sheep. Am J Physiol Lung Cell Mol Physiol. 2002;283:L104350 .

23. Chandra A, Katahira J, Schmalstieg FC, Murakami K, Enkhbaatar P, Cox RA, et al. P-selectin blockade fails to improve acute lung injury in sheep. Clin Scien. 2003;104:313-21.

24. Forlow SB, Ley K. Selectin-independent leukocyte rolling and adhesion in mice deficient in E-, P-, and L-selectin and ICAM-1. Am J Physiol Heart Circ Physiol. 2002;280:H634-41.

25. Umans JG, Wylam ME, Samsel RW, Edwards J, Schumacker PT. Effects of endotoxin in vivo on endothelial and smooth-muscle function in rabbit and rat aorta. Am Rev Respir Dis. 1993;148:1638-45.

26. Wang P, Ba ZF, Chaudry IH. Endothelium-dependent relaxation is depressed at the macro- and microcirculatory levels during sepsis. Am .J Physiol. 1995;269:R988-94.

27. Liao JK, Zulueta JJ, Yu FS, Peng HB, Cote CG, Hassoun PM. Regulation of bovine endothelial constitutive nitric oxide synthase by oxygen. J Clin Invest. 1995:96:2661-6.

28. Graier WF, Myers PR, Rubin LJ, Adams HR, Parker JL. Escherichia coli endotoxin inhibits agonist-mediated cytosolic $\mathrm{Ca}^{2+}$ mobilization and nitric oxide biosynthesis in cultured endothelial cells. Circ Res. 1994;75:659-68
29. Salvemini D, Korbut R, Anggard E, Vane J. Immediate release of a nitric oxide-like factor from bovine aortic endothelial cells by Escherichia coli lipopolysaccharide. Proc Natl Acad Sci USA. 1990;87:2593-7.

30. Wei XQ, Charles IG, Smith A, Ure J, Feng GJ, Huang FP, et al. Altered immune responses in mice lacking inducible nitric oxide synthase. Nature. 1995;375:408-11.

31. Gunnett CA, Chu Y, Heistad DD, Loihl A, Faraci FM. Vascular effects of LPS in mice deficient in expression of the gene for inducible nitric oxide synthase. Am J Physiol. 1998;275:H416-21.

32.

Bogle RG, MacAllister RJ, Whitley GS, Vallance P. Induction of NGmonomethyl-L-arginine uptake: a mechanism for differential inhibition of NO synthases? Am J Physiol. 1995;269:C750-6.

33. Wu CC, Ruetten H, Thiemermann C. Comparison of the effects of aminoguanidine and $\mathrm{N}$ omega-nitro-L-arginine methyl ester on the multiple organ dysfunction caused by endotoxaemia in the rat. Eur J Pharmacol. 1996;300:99-104.

34. Liaudet L, Fishman D, Markert M, Perret C, Feihl F. L-canavanine improves organ function and tissue adenosine triphosphate levels in rodent endotoxemia. Am J Respir Crit Care Med. 1997;21:1287-95.

35. Petros A, Lamb G, Leone A, Moncada S, Bennett D, Vallance P. Effects of a nitric oxide synthase inhibitor in humans with septic shock. Cardiovas Res. 1994;28:34-39.

36. Avontuur JA, Bruining HA, Ince C. Inhibition of nitric oxide synthesis causes myocardial ischemia in endotoxemic rats. Circ Res. 1995;76:41825.

37. Lorente JA, Landin L, De Pablo R, Renes E, Liste D. L-arginine pathway in the sepsis syndrome. Crit Care Med. 1993;21:1287-95.

38. Lopez A, Lorente JA, Steingrub J, Bakker J, McLuckie A, Willatts S, et al. Multiple-center, randomized, placebo-controlled, double-blind study of the nitric oxide synthase inhibitor 546C88: effect on survival in patients with septic shock. Crit Care Med. 2000;32:1287-95.

39. Multiple-center, randomized, placebo-controlled, double-blind study of the nitric oxide synthase inhibitor 546C88: effect on survival in patients of septic shock. Crit Care Med. 2004;32:21-30.

40. Gocan NC, Scott JA, Tyml K. Nitric oxide produced via neuronal NOS may impair vasodilatation in septic rat skeletal muscle. Am J Physiol Heart Circ Physiol. 2000;278:H1480-9.

41. Enkhbaatar P, Murakami K, Shimoda K, Mizutani A, McGuire R, Schmalstieg F, et al. Inhibition of neuronal nitric oxide synthase by $7-$ nitroindazole attenuates acute lung injury in an ovine model. Am J Physiol Regul Integr Comp Physiol. 2003;285:R366-72. 